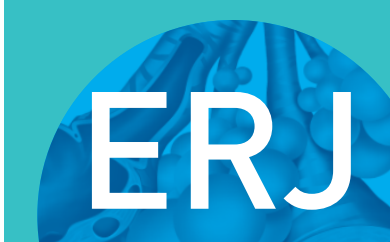

open research

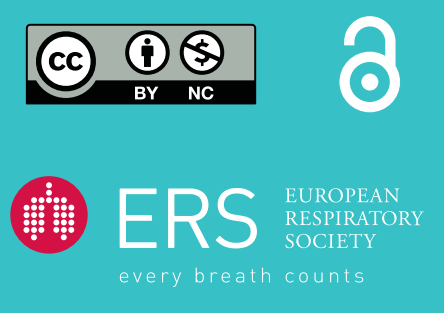

\section{Respiratory follow-up pre- and post- engineering controls or cessation of added diacetyl at four microwave popcorn facilities}

\section{To the Editor:}

We previously reported significant cross-sectional decrements in forced expiratory volume in $1 \mathrm{~s}\left(\mathrm{FEV}_{1}\right)$ from 2005 to 2006 among mixing room employees (mixers) with exposure to the butter flavouring diacetyl at four US microwave popcorn facilities [1]. Other studies with similar findings have been summarised by the US National Institute for Occupational Health and Safety (NIOSH) [2]. Diacetyl (2,3-butanedione) is a soluble diketone that vaporises when heated. Though use in the popcorn industry has declined, diacetyl has been documented in cigarette smoke, electronic cigarettes and coffee [2]. The aim of this follow-up study was to examine lung function in three cohorts. Cohort 1 began their employment before 2003, and aimed to identify any significant longitudinal decline among those with higher exposures and less extensive exposure controls. Cohort 2 began their employment between 2003 and 2007, and examined the impact of changes after implementation of additional exposure controls. Cohort 3 began their employment during or after 2008, when added diacetyl use was discontinued. These cohorts included all current full-time employees at the four facilities tested previously. Informed consent, and pulmonary and work histories were collected.

Pulmonary function tests (PFTs) were conducted on-site by technicians with NIOSH-certified training [1] in accordance with published guidelines [3]. All 4409 PFTs received expert review (R.T. McKay) for inclusion. Predicted values included the previously used 6\% lower adjustment for Asians [4, 5]. PFTs were administered three times in 2005, yearly from 2006 to 2009, and in 2011. There were 25 nonparticipants; 98\% participated at least once. Several Asian ethnicities were represented in Plant 4, which closed in 2007. Excluded from statistical analyses were office employees with minimal potential for exposure $(n=21)$, those with unusable PFTs or incomplete occupational histories $(n=9)$, and those having cardiovascular disease $(\mathrm{n}=3)$.

Diacetyl use in the facilities began in 1994. To reduce exposure, engineering and work practice changes were implemented in 2003-2005 including isolating the mixing rooms, increasing mixing room air ventilation, treating powders with $0.25 \%$ food grade oil to minimise dust, installing exhaust hoods for quality assurance operators, and in 2003, requiring mixers to wear powered air purifying respirators. Exposure monitoring began at all plants in 2005 [6]. Our previous job-exposure matrix [1, 6, 7] was utilised with these updates: additional ventilation controls in Plant 1 in June 2006 reduced mean exposures for nonmixers ( 0.07 to $0.02 \mathrm{ppm}$ ) and mixers (0.94 to $0.07 \mathrm{ppm}$ ); and subsequent sampling in Plant 2 demonstrated lower mean exposures for nonmixers (0.12 to $0.09 \mathrm{ppm}$ ) and mixers (0.84 to $0.61 \mathrm{ppm}$ ). While these measurements are considerably lower than in other studies [2], they exceeded the subsequent 2016 NIOSH Recommended Exposure Limit of 5 ppb [2]. Added diacetyl use was phased out late 2007 and 2,3-pentanedione was used for 1-2 months. In early 2008, the flavouring agents were reformulated and contained no added diacetyl, acetoin or 2,3-pentanedione. Sampling in 2008 after this change almost

@ERSpublications

In a 7-year study at 4 microwave popcorn facilities, mixing room employees exposed to diacetyl prior to the introduction of respirators showed significant loss of lung function but did not continue to decline longitudinally faster than other job categories http://bit.ly/2xwWRiw

Cite this article as: Lockey JE, Hilbert TJ, LeMasters G, et al. Respiratory follow-up pre- and postengineering controls or cessation of added diacetyl at four microwave popcorn facilities. ERJ Open Res 2019; 5: 00042-2019 [https://doi.org/10.1183/23120541.00042-2019]. 
exclusively gave results below the limit of detection for diacetyl. Cohort 1 (pre-2003) included 302 non-Asian males (NAMs), 47 Asian males, 181 non-Asian females (NAFs) and 64 Asian females. The Asian females were excluded from analyses as 62 out of 64 were in the "other" job category, and had minimal and homogenous exposure. The mean number of PFTs for cohort 1 was 4.9 and $85 \%$ had three or more PFTs. At the last PFT, their mean cumulative diacetyl was 0.9 ppm-years (range $0.1-$ 25.3 ppm-years), mean employment duration was 11.7 years (range 2.2-23.8 years) and mean tobacco exposure for ever-smokers was 20.6 pack-years (range 0.1-100 pack-years). The Asian males averaged longer employment and higher exposure estimates than NAMs and NAFs.

Cohort 2 (2003-2007) included 300 NAMs and 155 NAFs, each with mean of 2.7 PFTs. At the last PFT, their mean cumulative diacetyl exposure was $0.1 \mathrm{ppm}$-years (range 0.1-0.5 ppm-years), mean employment duration was 2.7 years (range 0.1-8.5 years) and mean tobacco exposure for ever-smokers was 15.0 pack-years (range 0.1-87.7 pack-years).

Cohort $3(\geqslant 2008)$ included 114 NAMs and 42 NAFs, with a mean of 1.6 and 1.8 PFTs, respectively. At the last PFT, their mean employment duration was 1.8 years (range $0.1-4.2$ years) and mean tobacco exposure for ever-smokers was 15.8 pack-years (range 0.1-74 pack-years).

Linear mixed regression models used all available PFTs to evaluate associations between exposure metrics and $\%$ predicted forced vital capacity (FVC) and $\mathrm{FEV}_{1}$ stratified by sex and race (Asian or non-Asian). Three exposure variables for cohort 1 included: 1) job category (pre-2003 mixer, pre-2003 intermittent mixer (maintenance and supervisors), pre-2003 quality assurance operator and other); 2) logarithmically transformed cumulative exposure at first PFT; and 3) duration of employment since 1994. Each model included an interaction term of time since first test (TSFT). TSFT adjusts for changes from the first to each subsequent test. Cohort 2 was analysed by current exposure at time of PFT $\times$ TSFT and employment duration. Few mixers began their employment after 2003, preventing a separate job category analysis. No Asians were included in cohort 2 or 3 as only 15 began their employment after 2003. Cohort 3 was analysed by employment duration since there was no current added diacetyl. All regression models were adjusted by body mass index (BMI) at first PFT, change in BMI since first PFT, current smoking status and pack-years of smoking.

Table 1 shows the primary analysis for cohort 1. Pre-2003 job categories of mixer, intermittent mixer and quality assurance operator as main effects and by interaction with TSFT were compared to other jobs. For NAMs, the main effects of pack-years of smoking, BMI at first PFT, BMI change and TSFT were consistently associated with significant losses in both \% predicted $\mathrm{FEV}_{1}$ and FVC. For the mixer category main effect there was a significant loss in $\%$ predicted $\mathrm{FEV}_{1}$ for NAMs $(n=27)$ and Asian males $(n=7)$ of $-7.92(\mathrm{p}<0.01)$ and $-13.7 \quad(\mathrm{p}<0.01)$, respectively. Asian male mixers had a significant loss of $\%$ predicted FVC of $-9.94(\mathrm{p}<0.02)$. No significant changes in the main effect were observed for NAF mixers $(\mathrm{n}=8)$ or any group within intermittent mixer or quality assurance job categories. A small but significant annual longitudinal decline was observed for NAF quality assurance operators $(n=20)$ for $\%$ predicted FVC of $-0.75(p=0.04)$ and was similar for FEV1 $(-0.71, \mathrm{p}=0.06)$. No similar annual longitudinal decline was noted for any group within the mixers or intermittent mixers. No group showed a significant longitudinal decline when evaluating logarithmically transformed cumulative exposure at first PFT $\times$ TSFT or employment duration $\times$ TSFT.

For cohort 2, current exposurexTSFT was not associated with any significant longitudinal decline in $\%$ predicted FVC or $\mathrm{FEV}_{1}$ for either NAFs or NAMs. Small but significant annual losses were observed for \% predicted FVC and $\mathrm{FEV}_{1}$ when employment duration was examined: for NAFs, $-0.31(\mathrm{p}=0.04)$ and -0.48 $(\mathrm{p}<0.01)$, and for NAMs $-0.47(\mathrm{p}<0.01)$ and $-0.65(\mathrm{p}<0.01)$, respectively. In cohort 3 , employment duration analysis showed no significant loss for either NAFs or NAMs.

In a post hoc analysis, we identified employees with at least five tests covering $>4$ years $(\mathrm{n}=291)$. An unadjusted regression line was plotted through each employee's $\mathrm{FEV}_{1}$ data and the slope was evaluated for accelerated decline of $>90 \mathrm{~mL} \cdot \mathrm{year}^{-1}$ as has been used by others $[8,9] .26(8.9 \%)$ of the 291 met these criteria: mixers, two $(9.1 \%)$ out of 22 ; intermittent mixers, six $(8.1 \%)$ out of 74 ; quality assurance operators, two $(18.2 \%)$ out of 11 ; and others, $16(8.7 \%)$ out of 184 . Of these 26 , six had normal lung function at the last PFT. Among the nonsmokers $(\mathrm{n}=112)$, the mean decline in $\mathrm{FEV}_{1}$ was $30.0 \mathrm{~mL} \cdot \mathrm{year}^{-1}$ and for ever-smokers $(n=179)$, the decline was $45.1 \mathrm{~mL} \cdot \mathrm{year}^{-1}$. To allow comparison of abnormal spirometry with other microwave popcorn facilities [2], results from the last PFT for cohorts 1 and 2 were: spirometric abnormities, $164(16.7 \%)$ out of 982 ; subdivided as restrictive, $n=79$; obstructive, $n=65$; and mixed, $\mathrm{n}=20$ (abnormal pattern definitions match those used by NIOSH) [8]. Three workers with invalid FVC at the last test were not included. The percentage of restrictive changes in workers with abnormal spirometry (79 out of $164,48.2 \%$ ) was similar to those documented in other diacetyl-exposed workers [2]. The overall rate of restrictive changes (79 out of $982,8.0 \%$ ) was increased compared to the US background rate of $5.4 \%$ [10]; the rate was similar between nonsmokers (31 out of 364, 8.5\%) and ever-smokers (48 out of $618,7.8 \%)$. We have previously reported on lung obstruction among these employees [1]. 
TABLE 1 Relationship between job category and lung function for those beginning their employment pre-2003 (cohort 1) by sex and racial group

\begin{tabular}{|c|c|c|c|c|c|c|}
\hline \multirow[t]{2}{*}{ Variable } & \multicolumn{2}{|c|}{ Non-Asian males ( $n=302$ ) } & \multicolumn{2}{|c|}{ Asian males ( $n=47)$} & \multicolumn{2}{|c|}{ Non-Asian females ( $n=181$ ) } \\
\hline & $\begin{array}{l}\text { Estimated change in } \\
\% \text { predicted } \mathrm{FEV} \\
\text { (p-value) }\end{array}$ & $\begin{array}{c}\text { Estimated change in } \\
\% \text { predicted FVC } \\
\text { (p-value) }\end{array}$ & $\begin{array}{c}\text { Estimated change in } \\
\% \text { predicted } \mathrm{FEV} \\
\text { (p-value) }\end{array}$ & $\begin{array}{l}\text { Estimated change in } \\
\% \text { predicted FVC } \\
\text { (p-value) }\end{array}$ & $\begin{array}{l}\text { Estimated change in } \\
\% \text { predicted FEV } \\
\text { (p-value) }\end{array}$ & $\begin{array}{c}\text { Estimated change in } \\
\% \text { predicted FVC } \\
\text { (p-value) }\end{array}$ \\
\hline Pack-years of smoking & $-0.30(<0.01)$ & $-0.13(<0.01)$ & $-0.13(0.27)$ & $-0.03(0.76)$ & $-0.31\{<0.01\}$ & $-0.16(0.05)$ \\
\hline Current smoker ${ }^{\#}$ & $-0.37(0.56)$ & $-0.08(0.88)$ & $-0.91(0.70)$ & $2.9(0.21)$ & $-0.90(0.32)$ & $0.15(0.86)$ \\
\hline BMI at first PFT & $-0.38(<0.01)$ & $-0.62(<0.01)$ & $-0.66(0.12)$ & $-1.13(<0.01)$ & $-0.14(0.35)$ & $-0.38(<0.01)$ \\
\hline BMI change since first PFT & $-0.45(<0.01)$ & $-0.43(<0.01)$ & $-0.39(0.36)$ & $-0.38(0.35)$ & $-0.2(0.01)$ & $-0.27(<0.01)$ \\
\hline Time since first PFT & $-0.57(<0.01)$ & $-0.55(<0.01)$ & $-0.39(0.51)$ & $0.75(0.19)$ & $-0.30(0.02)$ & $-0.23(0.04)$ \\
\hline Mixer & $-7.92(<0.01)$ & $-1.78(0.46)$ & $-13.7\{<0.01\}$ & $-9.94(0.02)$ & $4.13(0.44)$ & $-0.70(0.89)$ \\
\hline Intermittent mixer & $2.74(0.10)$ & $2.63(0.07)$ & $6.19(0.15)$ & $6.70(0.12)$ & $2.47(0.65)$ & $2.03(0.69)$ \\
\hline QA & $2.05(0.79)$ & $4.06(0.55)$ & NA & NA & $-1.38(0.70)$ & $-2.12(0.52)$ \\
\hline $\begin{array}{l}\text { Interaction mixerxtime } \\
\text { since first } \mathrm{PFT}^{\Uparrow}\end{array}$ & $0.02(0.96)$ & $-0.16(0.64)$ & $0.68(0.62)$ & $0.72(0.59)$ & $0.00(0.99)$ & $0.40(0.43)$ \\
\hline $\begin{array}{l}\text { Interaction intermittent } \\
\text { mixerxtime since first } \\
\text { PFT }^{\Uparrow}\end{array}$ & $0.41(0.06)$ & $0.27(0.17)$ & $0.88(0.34)$ & $-0.12(0.90)$ & $-0.77(0.12)$ & $-0.61(0.18)$ \\
\hline $\begin{array}{l}\text { Interaction QAxtime since } \\
\text { first PFT }\end{array}$ & $1.3(0.29)$ & $1.3(0.26)$ & NA & NA & $-0.71(0.06)$ & $-0.75(0.04)$ \\
\hline
\end{tabular}

Non-Asian males: mixers ( $n=27)$, intermittent mixers ( $n=111$ ), quality assurance operators (QA) ( $n=3)$, other ( $n=161)$; Asian males: mixers ( $=7$ ), intermittent mixers ( $n=6$ ), QA ( $=0$ ), other ( $n=34)$; non-Asian females: mixers ( $n=8)$, intermittent mixers ( $n=8), Q A(n=20)$, other ( $n=145)$. FEV ${ }_{1}$ : forced expiratory volume in 1 s; FVC: forced vital capacity; BMI: body mass index; PFT: pulmonary function test; NA: not applicable.": compared with never- and ex-smokers. ": compared to "others" defined as employees without employment as pre-2003 mixer, pre-2003 intermittent mixer (maintenance and supervisors) or pre-2003 QA operator. 
The primary analysis showed that in cohort 1 , only NAM and Asian male mixers demonstrated a significant loss in \% predicted $\mathrm{FEV}_{1}$ as they did in our previous cross-sectional analyses [1]. An additional finding was the significant loss in \% predicted FVC in Asian male mixers. Only quality assurance workers demonstrated significant longitudinal declines in \% predicted $\mathrm{FEV}_{1}$ and FVC. Two out of 11 quality assurance workers with at least five tests over $>4$ years had abnormal spirometry at time of the last test (one obstructive and one restrictive pattern). From our previous analysis [1], among the quality assurance workers in cohort $1(\mathrm{n}=23)$, there was one restrictive and one mixed pattern based on best of three tests in 2005. In contrast to a Missouri popcorn plant, no increased obstructive pattern was identified in the quality assurance operators [11]. In cohort 1, there was no association between logarithmic cumulative exposure or duration of employment and longitudinal decline. In cohort 2, employment duration but not current exposure was associated with annual decline in \% predicted $\mathrm{FEV}_{1}$ and $\mathrm{FVC}$.

In conclusion, the pre-2003 mixers, the work group at highest risk of an adverse impact from historical diacetyl exposure, demonstrated a significant but relatively stable loss in lung function over time. This study confirms an increased restrictive lung function pattern in microwave popcorn facility workers in comparison to the general population. The cause of significant parallel declines in \% predicted FVC and $\mathrm{FEV}_{1}$ in the quality assurance workers in cohort 1 , and especially the NAFs and NAMs in cohort 2, is not clear in view of lower cohort 2 cumulative exposures. One possible explanation is that chronic occupational exposure to diacetyl can result in low-grade bronchiolitis reflected by small annual decrements in both FVC and $\mathrm{FEV}_{1}$ parameters, and subsequent restrictive pattern. Historically, when full-shift exposures were higher and perhaps associated with short-term excursions, the health outcome was a more significant bronchiolitis resulting in airway obstruction and, in susceptible individuals, constrictive bronchiolitis. Loss of these workers from the workforce would result in observing a healthy worker effect that, with continuing employment, might be associated with a long-term impact from chronic low-grade bronchiolitis leading to a restrictive pattern.

Strengths of this study include length of follow-up, high participation rate, high-quality spirometry and measured full-shift exposures. A limitation is the lack of short-term peak exposure measurements and that pre-2005 exposures were assumed the same as those measured in 2005. Given the 2003-2005 exposure controls, this assumption may underestimate pre-2005 exposures, resulting in a potential exposure misclassification. However, samples from a 2003 NIOSH Health Hazard Evaluation [12] in Plant 1 were similar to those obtained in 2005 [6]. Exposures in Plant 1 may not be representative of other facilities. Furthermore, the follow-up time for cohort 3 may be insufficient to evaluate any potential hazard from the flavouring formulation used during that time. The 6\% adjustment used for Asians may be too small for some Asian ethnicities. In addition, the relatively small number of mixers and quality assurance workers limits overall statistical power, and the results can be impacted by outlying data points.

James E. Lockey ${ }^{1}$, Timothy J. Hilbert ${ }^{2}$, Grace LeMasters ${ }^{2}$, Kari K. Dunning ${ }^{2}$, Roy T. McKay ${ }^{2}$, Linda S. Levin ${ }^{2}$ and Carol H. Rice ${ }^{2}$

${ }^{1}$ University of Cincinnati College of Medicine, Depts of Environmental Health and Internal Medicine (Pulmonary Division), Cincinnati, OH, USA. ${ }^{2}$ University of Cincinnati College of Medicine, Dept of Environmental Health, Cincinnati, OH, USA.

Correspondence: James E. Lockey, Dept of Environmental Health, University of Cincinnati College of Medicine, 160 Panzeca Way, ML 0056, Cincinnati, OH 45267, USA. E-mail: james.lockey@uc.edu

Received: 14 Feb 2019 | Accepted after revision: 25 June 2019

Support statement: Collection of the historical data underlying this work was previously supported and funded by ConAgra Foods, Inc. Funding information for this article has been deposited with the Crossref Funder Registry.

Conflict of interest: J.E. Lockey reports grants from ConAgra Foods Inc. during the conduct of the study. T.J. Hilbert reports grants from ConAgra Foods Inc. during the conduct of the study. G. LeMasters reports grants from ConAgra Foods Inc. during the conduct of the study. K.K. Dunning reports grants from ConAgra Foods Inc. during the conduct of the study. R.T. McKay reports grants from ConAgra Foods Inc. during the conduct of the study. L.S. Levin reports grants from ConAgra Foods Inc. during the conduct of the study. C.H. Rice reports grants from ConAgra Foods Inc. during the conduct of the study.

\section{References}

1 Lockey JE, Hilbert TJ, Levin LP, et al. Airway obstruction related to diacetyl exposure at microwave popcorn production facilities. Eur Respir J 2009; 34: 63-71.

2 NIOSH. Criteria for a recommended standard: occupational exposure to diacetyl and 2,3-pentanedione (publication number 2016-111). www.cdc.gov/niosh/docket/archive/pdfs/niosh-245/245-FinalPublicationCD-Diacetyl-2016-111.pdf. Date last updated: October 2016. Date last accessed: May 14, 2019. 
Miller M, Hankinson J, Brusasco V, et al. Standardisation of spirometry. Eur Respir J 2005; 26: 319-338.

Hankinson JL, Odencrantz JR, Fedan KB. Spirometric reference values from a sample of the general U.S. population. Am J Respir Crit Care Med 1999; 159: 179-187.

5 Pellegrino R, Viegi G, Brusasco V, et al. Interpretative strategies for lung function tests. Eur Respir J 2005; 26 : 948-968.

6 White KL, Heikkila K, Williams R, et al. Diacetyl exposures at four microwave popcorn plants. JOEH 2010; 7: $185-193$.

7 White KL. Letter to the Editor. JOEH 2011; 8: D25-D26.

8 NIOSH. Hazard evaluation and technical assistance report: Lung function (spirometry) testing in employees at a flavorings manufacturing plant-Indiana. (NIOSH HETA Report No. 2008-0155-3131). www.cdc.gov/niosh/hhe/ reports/pdfs/2008-0155-3131.pdf. Date last updated: June 2011. Date last accessed: May 14, 2019.

9 Redlich CA, Tarlo SM, Hankinson JL, et al. Official American Thoracic Society Technical Standards: Spirometry in the Occupational Setting. Am J Respir Crit Care Med 2014; 189: 984-994.

10 Kurth L, Hnizdo E. Change in prevalence of restrictive lung impairment in the U.S. population and associated risk factors: the National Health and Nutrition Examination Survey (NHANES) 1988-1994 and 2007-2010. Multidiscip Respir Med 2015; 10: 7.

11 NIOSH. Health hazard evaluation report: Glister-Mary Lee Corporation, Jasper, MO. (NIOSH HETA report number 2000-0401-2991). Date last updated: January 2006. Date last accessed: July 30, 2019. www.cdc.gov/niosh/ hhe/reports/pdfs/2000-0401-2991.pdf.

12 NIOSH. Health hazard evaluation report: ConAgra Snack Foods, Marion, OH (NIOSH HETA report number 2003-0112-2949). www.cdc.gov/niosh/hhe/reports/pdfs/2003-0112-2949.pdf. Date last updated: December 2004 Date last accessed: May 14, 2019. 